\title{
Vantagem Competitiva no Turismo Rural: Análise dos Recursos Estratégicos de Hotéis fazenda
}

\author{
Luana de Oliveira Alves ${ }^{a}$ \\ Luana Alexandre Silvab \\ Viviane Santos Salazarc
}

\section{Resumo}

A possibilidade de experimentar atividades diferentes do agito do cotidiano e de ter um contato mais íntimo com a natureza tem direcionado muitos turistas para o campo. Para explorar esse nicho de mercado o empresário do setor rural passa a ser um estrategista em busca de novas possibilidades de negócio que atendam a esta demanda. Na área da gestão estratégica, uma das questões que vem despertando atenção dos estudiosos diz respeito à razão que permite às empresas desenvolverem e manterem vantagem competitiva em relação aos demais concorrentes. Seguindo este raciocínio, este trabalho analisa os hotéis-fazenda a partir da perspectiva da RBV (Visão Baseada em Recursos), cuja teoria considera os fatores internos de uma empresa como determinantes do seu desempenho superior. 0 objetivo desta pesquisa é, portanto, identificar e avaliar quais recursos estratégicos sustentam a vantagem competitiva dos hotéis-fazenda a partir da análise de dois empreendimentos: um localizado no Estado do Ceará e outro em Pernambuco. Trata-se de uma pesquisa de natureza descritiva que adotou como instrumentos de coleta de dados um questionário aberto, além de uma entrevista semiestruturada para aprofundamento das informações obtidas. Dentre as observações realizadas no decorrer do estudo foi possível identificar que os recursos físicos, como a localização, e os recursos humanos, em especial o atendimento, podem ser vistos como recursos estratégicos que sustentam a vantagem competitiva deste tipo de empreendimento.

Palavras-chave: Recursos Estratégicos; Turismo Rural; Hotéis-Fazenda; RBV.

\section{Abstract \\ Competitive Advantage in Rural Tourism: Analysis the Strategic Resources by Farm Hotels}

The possibility of experiencing activities different from the everyday agitation and having a more intimate contact with nature has directed many tourists to the countryside. To exploit this niche market the rural entrepreneur becomes a strategist in search of new business possibilities that meet this demand. In the area of strategic management, one of the issues that has attracted attention from scholars is the reason that allows companies to develop and maintain a competitive advantage over other competitors. Following this reasoning, this work analyzes the farm-hotels from the perspective of RBV (Resource Based View), whose theory considers the internal factors of a company as determinants of its superior performance. The objective of this research is, therefore,

a. Doutoranda em administração na Universidade Federal de Pernambuco - UFPE, Recife, Pernambuco, Brasil. E-mail: admluanaalves@gmail.com.

b. Doutoranda em administração na Universidade Federal de Pernambuco - UFPE, Recife, Pernambuco, Brasil. E-mail: luanaalsilva@gmail.com

c. Doutora em administração na Universidade Federal de Pernambuco - UFPE, Recife, Pernambuco, Brasil. E-mail: viviane_salazar@yahoo.com.br 
to identify and evaluate the strategic resources that support the competitive advantage of farm hotels based on the analysis of two enterprises: one located in the State of Ceará and the other in Pernambuco. It is a research of a descriptive nature that adopted as an instrument of data collection an open questionnaire, in addition to a semi-structured interview to deepen the information obtained. Among the observations made during the study, it was possible to identify that physical resources, such as location, and human resources, especially customer service, can be seen as strategic resources that support the competitive advantage of this type of enterprise.

Keywords: Strategic Resources; Rural Tourism; Farm-House; RBV.

\section{Resumen}

Ventaja Competitiva en Turismo Rural: Análisis de los Recursos Estratégicos para Hoteles rurales

La posibilidad de probar diferentes actividades ajetreo de cada día y tener un contacto más íntimo con la naturaleza ha atraído a muchos turistas al país. Para explotar este nicho de mercado la empresa en el sector rural se convierte en un estratega en busca de nuevas oportunidades de negocio que satisfagan esta demanda. En el área de la gestión estratégica, una de las cuestiones que vienen mereciendo atención de los estudiosos tiene que ver con la razón que permite a las empresas desarrollar y mantener una ventaja competitiva en relación a los otros adversarios. Según esta línea de pensamiento, este trabajo analiza los hoteles rurales desde la perspectiva de la RBV( Visión Basada en los Recursos) cuya teoría considera que los factores internos de una empresa como determinantes de su rendimiento superior. El objetivo de esta investigaciones, por lo tanto, identificar y evaluar los recursos estratégicos que sustentan la ventaja competitiva de hoteles agrícolas a partir del análisis de dos proyectos: uno ubicado en el Estado de Ceará y uno en Pernambuco. Se trata de una investigación descriptiva que adoptó como instrumentos de recolección de datos un cuestionario abierto, y una entrevista telefónica semiestructurada para profundizar en la información obtenida. Entre las observaciones hechas durante el estudio fue posible identificar los recursos físicos tales como la ubicación, y los recursos humanos, en particular el servicio puede ser visto como recursos estratégicos que sustentan la ventaja competitiva de este tipo de empresa.

Palabras clave: Recursos Estratégicos; Turismo Rural; Hoteles Rurales, RBV.

\section{INTRODUÇÃO}

O campo é o segundo destino preferido dos turistas brasileiros, atrás apenas das praias (BRASIL, Ministério do Turismo, 2013). Ao fugir das grandes cidades e dos destinos turísticos tradicionais, os viajantes encontram no campo a possibilidade de experimentar atividades diferentes das que vivenciam no agito do seu cotidiano e junto a isso ter um contato mais íntimo com a natureza. Essa possibilidade faz com que os turistas apreciem cada vez mais essa forma de fazer turismo, conhecida como turismo rural (BRASIL, Ministério do Turismo, 2013).

Com o interesse crescente pelo campo, a percepção do meio rural passa a transcender ao mero aproveitamento da terra, englobando práticas cada vez mais diversificadas de utilização, como as atividades ligadas ao lazer e a prestação de serviços de alimentação e hospedagem (OKECH; HAGHIRI; GEORGE, 2012). Neste panorama, o empresário do setor rural precisa ser também um estrategista para explorar as novas oportunidades de negócios trazidas pelo ambiente rural, 
avaliando a realidade ao qual está inserido e verificando a viabilidade da permanência neste meio (BROOKER e JOPPE, 2013; ROQUE e VIVIAN, 1999).

Diversos são os serviços que podem ser realizados no meio rural e que atraem os turistas para o campo, como o arvorismo e as trilhas ecológicas, por exemplo. Para fins desta pesquisa será dada ênfase aos hotéis-fazenda, sendo estes equipamentos considerados peças chaves para o bom desenvolvimento do turismo rural em determinada localidade. Ao oferecer atividades relacionadas ao campo e possibilitar ao turista vivenciar o cotidiano rural, inclusive participando da rotina local (BROOKER e JOPPE, 2013; ROQUE e VIVIAN, 1999), este empreendimento pode contribuir significativamente com o aprimoramento deste tipo de turismo que visa agregar valor a região e promover o patrimônio natural e cultural da localidade (BRASIL, Ministério do Turismo, 2003).

Os hotéis-fazenda se diferenciam dos demais tipos de hospedagem por utilizarem o espaço rural como um dos recursos de maior atratividade. Porém, existem diversos outros recursos que são importantes para mantê-los competitivos e que podem ser estudados por pesquisadores da administração estratégica. Algumas das questões que despertam interesse desses pesquisadores e que podem ser aplicadas aos diversos tipos de serviços, dizem respeito às razões que permitem às empresas desenvolverem e manterem vantagem competitiva em relação às suas concorrentes. Para analisar essas questões, o paradigma da Estrutura- Conduta- Desempenho (ECD) defendido por Michael Porter recebe até hoje significativa aceitação. Segundo esta linha de pensamento, o desempenho das empresas seria fundamentalmente determinado pela estrutura da indústria e pela conduta, ou seja, pela estratégia adotada pelas empresas (PORTER, 1986).

Outra linha teórica corrente, por sua vez, defende os fatores internos como importantes determinantes para esse desempenho superior. Esta teoria, proposta pela Visão Baseada em Recursos (RBV), surgiu com o objetivo de desenvolver ferramentas para analisar a posição da empresa frente aos recursos por ela utilizados e, a partir disso, propor opções de estratégias a serem seguidas pela organização (WERNERFELT, 1984). Segundo a RBV, os recursos específicos são determinantes para a geração de lucro das empresas. Essa visão contribui para os estudos da vantagem competitiva argumentando que uma empresa para ter vantagem competitiva é necessário implementar uma estratégia de criação de valor que não seja utilizada ao mesmo tempo por nenhum concorrente (BARNEY, 1991; GRANT, 1991).

Com base nesta perspectiva e considerando o panorama do turismo rural, este estudo se destina a identificar os recursos estratégicos e avaliar quais os recursos estratégicos que sustentam a vantagem competitiva dos hotéis-fazenda, sendo estes entendidos como peças fundamentais no desenvolvimento deste setor. Espera-se com isso, contribuir com o avanço do conhecimento científico na área e possibilitar aos gestores dos empreendimentos turísticos rurais uma análise do seu negócio sob o ponto de vista dos aspectos internos dos mesmos.

Quanto à estrutura deste artigo, está dividida em cinco seções além desta introdução. A primeira parte do referencial teórico aborda os conceitos básicos do turismo rural e o papel dos hotéis-fazenda neste cenário. A segunda parte traz um breve panorama a respeito da teoria da Visão Baseada em Recursos - RBV. Em seguida é apresentada a descrição dos métodos utilizados, a apresentação 
e análise dos dados coletados e, por fim, as considerações finais com as devidas contribuições do estudo.

\section{Entendendo o Turismo Rural e os Hotérs-Fazenda}

O turismo rural, caracterizado pelo conjunto de atividades turísticas desenvolvidas no meio rural e comprometidas com a produção agropecuária, se destaca das demais modalidades de turismo por agregar valor aos produtos e serviços fornecidos na região em que se desenvolve, além de promover o patrimônio cultural e natural da comunidade em que está inserido (BRASIL, Ministério do Turismo, 2003).

A ampliação da oferta turística em áreas rurais, bem como de estudos e pesquisas científicas relacionadas a este tipo de turismo, tornou-se perceptível no Brasil a partir da década de 90, apesar desta atividade ter iniciado o seu crescimento na Europa e nos Estados Unidos na década de 1960, em virtude do desenvolvimento econômico advindo da industrialização e das conquistas trabalhistas angariadas pós Segunda Guerra Mundial (CANDIOTTO, 2010; TULIK, 2003).

Desde 1990, quando o turismo rural passou a ser visto como alternativa de desenvolvimento local para a Europa e para o mundo, o interesse por esta atividade passou a crescer significativamente em decorrência da procura constante dos turistas por atrativos que proporcionassem a tranquilidade não encontrada nos centros urbanos, o contato com a vida simples do campo e também o desenvolvimento sustentável da localidade visitada (CANDIOTTO, 2010).

Diversas definições têm sido relacionadas ao turismo rural tamanha é a abrangência desta atividade. Beni (2002) associa esta modalidade de turismo ao deslocamento para áreas rurais no intuito de usufruir do cenário e das instalações rurícolas. Já outros autores vão considerar qualquer tipo de atividade exercida no meio rural como sendo parte do turismo rural. Candiotto (2010) separa as atividades exercidas no espaço rural, como o agroturismo e o ecoturismo, das atividades que envolvem a produção rural tradicional, como a agricultura e a pecuária, sendo estas últimas consideradas de fato como características do turismo rural.

Embora exista uma vasta discussão sobre a conceitualização desta modalidade de turismo, será considerada para fins desta pesquisa a definição de turismo rural defendida por Candiotto (2010) em concordância com Silva e Almeida (2002) que restringem este setor aos casos em que as atividades tradicionais do meio rural desempenhem papel fundamental na estadia do turista, sendo este um participante destas ou apenas observante.

Este conceito de turismo rural foi também considerado para análise dos empreendimentos turísticos utilizados neste estudo no intuito de identificar se os recursos estratégicos dos hotéis-fazenda têm contribuído para o fortalecimento desta atividade. A propósito, por empreendimentos turísticos, compreendem-se as instalações e serviços que são fundamentais para o desenvolvimento da atividade turística em determinada localidade (LOHMANN; PANOSSO NETTO, 2008; BARRETO, 1991). Neste estudo, serão analisados apenas os hotéis-fazenda, tipo específico de empreendimento turístico no ambiente rural. 
Considerando a diversidade de negócios que fazem parte da indústria do turismo, inclusive do turismo rural, pode-se observar que os empreendimentos hoteleiros exercem um papel de importância fundamental no desenvolvimento e manutenção desta atividade. Ao fazerem parte da própria oferta turística local e serem responsáveis também pela caracterização e ampliação da demanda de turistas para determinada localidade, o setor de hospedagem pode ser identificado como um dos principais pilares do turismo em uma região (GOHR; SANTOS, 2010). Em algumas áreas rurais, por exemplo, o hotel-fazenda por si só pode ser o principal ou o único atrativo turístico existente na cidade, podendo ser ao mesmo tempo a motivação e a estrutura de apoio para os turistas que o procuram.

Além da dinamicidade do setor, as mudanças constantes de mercado e a competitividade acirrada na hotelaria evidenciam o desafio e a necessidade dos gestores em desenvolverem recursos estratégicos que promovam o desenvolvimento sustentável de seu empreendimento. A grande diversidade de destinos e de formas de hospedagem (como albergues e aluguéis por temporada, por exemplo), a presença de redes nacionais e internacionais no setor hoteleiro, os novos modelos de negócio do consumo colaborativo, a busca constante pela satisfação do turista, além da importância de adquirir reconhecimento e legitimidade no mercado são aspectos que reforçam a necessidade de aprimorar os processos de administração estratégica dos hotéis, ampliando o seu grau de profissionalização (WILKE; RODRIGUES, 2013).

Em acréscimo a estes fatores, a hotelaria possui algumas peculiaridades que desafiam a administração estratégica por parte dos gestores. A necessidade constante de investimento na modernização da infraestrutura do hotel é um exemplo (GOHR; SANTOS, 2010). Sobre este aspecto, Gorini e Mendes (2005) ressaltam que estes equipamentos turísticos precisam passar por reformas consideráveis em média a cada 10 anos, em virtude do risco de perderem vantagem competitiva sob os demais concorrentes do mercado.

Sendo assim, as estratégias adotadas pelas empresas de serviços turísticos possuem caráter determinante sobre a atividade turística de uma localidade (GOHR; SANTOS, 2010; SILVA; BARRETO, 2015), o que requer uma atenção contínua por parte da organização no intuito de manter e ampliar a sua competitividade e sobrevivência no mercado (SILVA; BARRETO, 2015).

No campo da ciência, pesquisas têm analisado as estratégias utilizadas por destinos e empresas turísticas, principalmente no que diz respeito à área de marketing (STOKES, 2008). Quanto aos estudos que analisam especificamente a estratégia de empresas do setor hoteleiro, é possível encontrar temas como performance e vantagem competitiva individual, cluster turísticos (SANTOS, 2007) e competitividade (GOHR; SANTOS, 2010), conforme assinalam Wilke e Rodrigues (2013).

Sobre a RBV e a hotelaria, destacam-se os estudos de Santos, Gohr e Cruz (2011) que abordam hotéis do Mato Grosso do Sul com alto fluxo de turistas de negócios e as pesquisas de Zonatto, Schuh e Zonatto (2014) que relacionam os recursos estratégicos, a inovação e a cooperação em rede em três organizações hoteleiras situadas no Rio Grande do Sul e em Santa Catarina.. 


\section{Entendendo a Visão Baseada em Recursos - RBV}

Conhecida como Resource Based View (RBV), a visão baseada nos recursos tem origem nos estudos de Edith Penrose que em 1959 pesquisou o crescimento das firmas e atribuiu as causas deste não apenas aos fatores externos, mas também aos fatores internos derivados do conjunto de recursos da firma. Em outras palavras, as firmas passaram a ser vistas como um portfólio de recursos em vez de um portfólio de produtos, e o lucro da empresa é dependente dos recursos que ela possui (PENROSE, 2006; WERNERFELT, 1984). Assim, quanto maiores os recursos e competências possuídos por uma empresa, maior será o seu lucro.

A partir das ideias de Penrose, Wernerfelt (1984) passa a usar o termo Visão Baseada em Recursos, impulsionando vários estudiosos a tentarem explicar como as empresas possuem diferentes performances estando situadas em uma mesma indústria. Esses estudos passaram então a considerar os recursos que as empresas possuíam e que mantinham a sua competitividade.

Segundo Barney e Hesterly (2011), a RBV baseia-se em duas premissas: a heterogeneidade de recursos, que significa que empresas diferentes podem possuir recursos distintos mesmo competindo num mesmo setor; e a imobilidade de recursos, que diz respeito ao fato de que tanto os recursos como as capacidades podem ter custos muito altos para serem desenvolvidos ou adquiridos.

O sentido que a palavra "recursos" possui na RBV está muito além dos bens tangíveis da empresa, pois se estende a "todos os ativos" de uma organização, incluindo as competências, o conhecimento e os atributos que lhe permitem implementar estratégias visando a sua eficiência e eficácia no mercado. Isso quer dizer que as organizações começam a serem vistas como um conjunto de recursos, sendo estes tangíveis ou intangíveis (BARNEY, 1991; WERNERFELT, 1984).

Seguindo este raciocínio, os recursos podem ser classificados em quatro categorias, conforme exemplificado a seguir, no quadro 1:

Quadro 1 - Classificação dos recursos

\begin{tabular}{l|l|}
\hline $\begin{array}{l}\text { Todo dinheiro de empreendedores, acionistas, credores, bancos além } \\
\text { dos lucros retidos utilizados para criar e implementar estratégias. }\end{array}$ & $\begin{array}{l}\text { Recursos } \\
\text { financeiros }\end{array}$ \\
\hline $\begin{array}{l}\text { Toda a tecnologia física como equipamentos de hardware e software, } \\
\text { além da localização geográfica. }\end{array}$ & Recursos físicos \\
\hline $\begin{array}{l}\text { Treinamentos, experiência, inteligência, relacionamento, visão dos } \\
\text { gerentes e demais funcionários. }\end{array}$ & Recursos humanos \\
\hline $\begin{array}{l}\text { Estrutura formal de reporte da empresa, sistemas formais e informais } \\
\text { de planejamento, controle e coordenação, cultura e reputação, além das } \\
\text { relações informais entre os grupos. }\end{array}$ & $\begin{array}{l}\text { Recursos } \\
\text { organizacionais }\end{array}$ \\
\hline
\end{tabular}

Fonte: Barney e Hesterly (2011)

Tais recursos podem ser vistos como determinantes dos ganhos e da vantagem competitiva de uma organização, embora nem todos possam gerar altos níveis de ganho econômico. Para que os recursos possam ser considerados estratégicos, ou seja, gerem vantagem competitiva, eles devem ser simultaneamente: valiosos; raros entre as firmas concorrentes e potenciais concorrentes; imperfeitamente imitáveis; não serem estrategicamente substituíveis por outro recurso (imperfeitamente substituíveis) e organizáveis (explorado pela organização). A partir 
desse conjunto de características é que surge o modelo VRIO, que significa: Valor, Raridade, Imitabilidade e Organização (BARNEY e HESTERLY, 2011).

A aplicabilidade do modelo VRIO permite avaliar cada recurso ou uma capacidade (que não é o foco deste trabalho) em termos de geração de vantagem competitiva. A ideia é que se o recurso é valioso, isto é, "quando permitem que uma empresa conceba ou coloque em prática estratégias que melhorem sua eficiência e eficácia" (BARNEY, p.103, 1991), mas não é raro, sua exploração para desenvolvê-lo gerará paridade competitiva, ou seja, outras empresas concorrentes também podem ter o mesmo recurso e deixar de explorá-lo pode colocar o empreendimento em desvantagem competitiva. Se um recurso é valioso e raro, mas o custo para imitá-lo não é oneroso a empresa terá uma vantagem competitiva temporária já que a qualquer momento outra empresa pode adquiri-lo ou desenvolvê-lo. Agora considere que o recurso é valioso, raro e difícil de imitar, explorar esse recurso gerará uma vantagem competitiva sustentável já que para uma empresa concorrente imitá-lo desprenderá de um alto custo colocando-a em desvantagem (BARNEY e HESTERLY, 2011).

Vale ressaltar que para que haja vantagem competitiva é necessário que a estratégia agregue valor à empresa sem que o outro concorrente possa "imitá-la" com facilidade. Isso não quer dizer que a vantagem competitiva durará para sempre, mas apenas que esta não seria superada pela concorrência (BARNEY, 1991). Nesse sentido, compreende-se que a empresa possui vantagem competitiva quando é capaz de gerar maior valor econômico do que os seus concorrentes (BARNEY e HESTERLY, 2011).

Ao abordar a vantagem competitiva, Grant (1991) aponta quatro características dos recursos e das capacidades que são determinantes para a sua sustentabilidade: durabilidade, transparência, transferência e replicabilidade (este último entende-se como a imitabilidade de Barney, 1991).

Tal qual Grant (1991), Peteraf (1993) também trata sobre a vantagem competitiva só que diferentemente, elabora um modelo geral de recursos e desempenho capaz de integrar as várias tendências de pesquisa e oferecer um denominador comum, ou seja, facilitar o contínuo diálogo entre os estudiosos. Esse modelo de vantagem competitiva apresenta algumas condições que precisam ser satisfeitas para que a empresa desfrute dos lucros. Uma das condições proposta por Peteraf (1993) é a heterogeneidade dos recursos, pressuposto básico dos trabalhos baseados em recursos como cita também Barney (1991). Segundo esse pressuposto, a heterogeneidade é presumida pela vantagem competitiva e causa diferenças de performance econômica nas empresas já que algumas apresentam baixa lucratividade e outras lucratividade alta em relação a média do mercado. Sendo assim, o controle das firmas para esses recursos que geram desempenho superior pressupõe que a oferta desses recursos seja limitada e que essa restrição pode ser temporária ou permanente (VASCONCELOS e CYRINO, 2000).

Consoante à literatura explorada e para fins deste trabalho, o modelo VRIO será considerado para avaliar os recursos identificados, isto é, analisando cada característica de valor, raridade, imitação e organização para que seja possível atingir o objetivo deste estudo e, portanto, avaliar os recursos que sendo explorados pela organização proporcionarão algum tipo de vantagem competitiva para as organizações em análise. 


\section{Metodologia}

A pesquisa realizada para este estudo possui natureza descritiva, pois tem o interesse de descrever os recursos estratégicos que são vistos como fontes de vantagem competitiva para os hotéis-fazenda analisados. Conforme Gil (2009), esse tipo de pesquisa tem como objetivo principal a descrição das características de determinada população ou fenômeno ou, então, estabelecer a relação entre variáveis.

Utilizou-se da abordagem qualitativa de estudo de caso, estratégia de pesquisa que busca responder "como" e por que" determinados fenômenos ocorrem (YIN, 2005). A unidade de análise consistiu em dois hotéis-fazenda situados um em Pernambuco e outro no Ceará, sendo ambos os equipamentos turísticos de destaque para o turismo rural destes Estados. Por questões de sigilo, os empreendimentos serão representados como Hotel A e Hotel B. Inicialmente buscou-se identificar as características de cada hotel e a forma como funcionam. A partir de perguntas abertas foi possível identificar os recursos utilizados pelos empreendimentos e categorizá-los segundo a definição de Barney e Hesterly (2011) como recursos físicos, humanos, organizacionais e financeiros. Em seguida, procurou-se avaliar os recursos de acordo com o modelo VRIO discutido anteriormente. Ressalta-se que nesta pesquisa foram realizados dois estudos de caso realizados em empresas que estão situadas em localidades distintas.

Os dados utilizados no estudo provêm de fontes primárias, alcançados a partir dos relatos dos gestores e/ou proprietários dos hotéis em análise como também da observação de portais online dos empreendimentos, como sites e mídias sociais, além de sites de viagens para verificar os comentários dos clientes sobre o hotel. Entretanto, registram-se principalmente neste artigo as informações fornecidas pelos gestores, dado que o foco recai sobre sua capacidade de desenvolver o negócio a partir da perspectiva do recurso.

Os empreendimentos participantes foram escolhidos de acordo com a acessibilidade e a disponibilidade para participação na pesquisa, além da representatividade que possuem no setor. Procurou-se por aqueles que tivessem sites, assim poderíamos explorar as informações em conformidade com os dados obtidos através do questionário.

Quanto aos instrumentos de coleta de dados, utilizou-se de um roteiro com questões abertas que foi enviado por email e respondido pelos gestores dos estabelecimentos pesquisados. Utilizou-se esta ferramenta a pedido dos próprios respondentes pela questão de tempo e facilidade. Após o retorno dos questionários realizou-se uma entrevista semiestruturada por telefone para complementação dos dados obtidos. O período de realização foi o mês de julho de 2016.

\section{Apresentação e ANÁLise dos dados}

Com as informações coletadas a partir dos questionários e as informações institucionais disponíveis na internet, foi possível construir um panorama geral sobre cada empreendimento pesquisado de forma a caracterizar cada um em termos de funcionamento. 


\section{a) Hotel $A$}

O hotel-fazenda A está localizado em uma rodovia do Estado do Ceará e já existe no segmento há mais de cinco anos. Com uma área de 500 mil metros quadrados, o empreendimento possui em sua propriedade lagos, mirantes e diversas plantações, como cana-de-açúcar, café, laranja, abacate, manga (da qual se fabrica a polpa), entre outras, além de uma horta. 0 hotel ainda possui academia, campo de vôlei, campo society, 2 piscinas infantis e 1 piscina para adulto, restaurante e cafeteria. 0 valor da diária para casal varia entre $\mathrm{R} \$ 250,00$ para apartamento standard a $\mathrm{R} \$ 350,00$ para suítes de luxo, no período de baixa estação. No período do réveillon as diárias para casal chegam a $\mathrm{R} \$ 600,00$.

Há uma diversidade de atividades possíveis de serem realizadas na localidade, como passeio de cavalo, de charrete, tirolesa do bosque, tirolesa do lago, passeio de trator, vista do mirante, trilhas, cachoeiras, escalada. Há também atividades sazonais como música ao vivo no restaurante, show com fogueira, bingos nordestinos, cinema para crianças. Quanto a estrutura do hotel, este possui 48 apartamentos e mais 8 em construção, além de uma loja de conveniência. Sobre a infraestrutura a gerência destaca atenção especial neste quesito informando que todo ano o hotel passa por expansão. Ainda segundo a gerência, o empreendimento é considerado o hotel com maior estrutura da região do Ceará recebendo turistas de vários locais do país, principalmente piauienses (em torno de 50\%).

Sobre a mão de obra, trinta funcionários estão envolvidos no negócio, sendo o grau de qualificação da maioria ensino médio completo, havendo apenas 4 ou 5 colaboradores com nível superior. A sociedade é formada por três sócios que fazem parte de uma mesma família e um dos gerentes/proprietário do hotel é formado em administração, mas auxilia também em atividades pontuais quando necessário.

\section{b) Hotel $B$}

O hotel-fazenda B existe há 9 (nove) anos e está localizado no interior de Pernambuco, com estrutura para 78 apartamentos e diária com valor médio de $\mathrm{R} \$$ 450,00 para quarto duplo. Iniciou suas atividades como uma simples pousada que foi crescendo de acordo com a demanda do mercado e a atenção da mídia para aquela região. A fazenda foi adquirida por um dos sócios (são três sócios membros de uma mesma família) há 12 anos e o mesmo já comprou o terreno pensando em criar algum negócio voltado ao turismo rural ou ecoturismo.

Com aproximadamente 80 hectares, o hotel está situado em área de preservação ambiental e possui estrutura equipada com parque aquático com 03 piscinas (sendo uma infantil), campo de futebol, cascatas naturais, salão de jogos, 04 lagos, cachoeira privativa, restaurante, espaço fechado para eventos, além de plantações de frutas, hortaliças e raízes. Entre as atividades de lazer oferecidas pelo hotel estão trilhas ecológicas, ordenha, pesca esportiva, pesque e pague, stand up paddle no lago - esporte que consiste em remar em pé na prancha de surfe -, passeio de cavalo, tirolesa. Pode-se também assar milho na fogueira, alimentar animais, visitar plantações, dançar forró pé de serra, passear de quadriciclo, realizar balonismo e observar o pôr do sol em local de importância histórica para o país.

No momento da pesquisa o hotel contava com 40 funcionários, cujo grau de qualificação varia entre pessoas com ensino médio completo, técnico, graduação e também mestrado. A gerência possui conhecimentos formais em turismo, ad- 
ministração, direito e economia. Cabe ressaltar que o empreendimento já recebeu diversos prêmios por suas ações e serviços.

\section{Em busca dos recursos estratégicos nos Hotéis-Fazenda}

Baseada na classificação de recursos estabelecida por Barney e Hesterly (2011), as características de cada hotel foram relacionadas e separadas de acordo com o tipo de recurso identificado. Estas informações estão resumidas nos quadros 2 e 3. Posteriormente, descreveram-se os recursos com maiores detalhes para facilitar o entendimento das relações estabelecidas.

A) Hotel $A$

Quadro 2 - Recursos do Hotel A

\begin{tabular}{l|l|}
\multicolumn{1}{c|}{ Características Hotel A } & \multicolumn{1}{c|}{ Recursos } \\
\hline $\begin{array}{l}\text { Localização; } \\
\text { Condições agronômicas vantajosas; } \\
\text { Qualidade na infraestrutura; } \\
\text { Rampas de acesso e quartos apropriados para pessoas com mobilidade } \\
\text { reduzida; } \\
\begin{array}{l}\text { Espaços diferenciados para crianças; } \\
\text { Diversidade de atividades de lazer. }\end{array}\end{array}$ & Físicos \\
\hline $\begin{array}{l}\text { Reserva de capital (recursos próprios); } \\
\text { Ativos (lucros de outro empreendimento) }\end{array}$ & \\
\hline $\begin{array}{l}\text { Mão de obra qualificada com cursos no SEBRAE; } \\
\text { Funcionários polivalentes; } \\
\text { Hospitalidade e atendimento diferenciado. }\end{array}$ & Financeiros \\
\hline $\begin{array}{l}\text { Estrutura hierárquica; } \\
\text { Comprometimento dos funcionários; }\end{array}$ & Humanos \\
\hline
\end{tabular}

Fonte: Dados da pesquisa

Sobre os recursos físicos, o Hotel A conta com várias características que são semelhantes a outros hotéis-fazenda, como as atividades de lazer (passeio de cavalo, tirolesas trilhas, por exemplo) e os espaços diferenciados para o público infantil (como piscinas e playground). Diferencia-se, entretanto, por proporcionar ocupações como paredão de escaladas e cineminha, sucesso entre a criançada. 0 interesse em direcionar parte dos recursos para as crianças é notável nas ações do hotel, inclusive no discurso da gestão que afirma ser essa a maior estratégia de marketing do hotel: "depois de três a quatro meses a criança está pedindo aos pais para voltar, além de divulgar na escola para os amiguinhos".

Outro recurso físico fundamental para o hotel é a localização geográfica, pois está situado em uma região com serra, onde o clima é agradável e as temperaturas variam entre 16 a $20^{\circ} \mathrm{C}$. A altitude do local facilita o desenvolvimento de atividades como a tirolesa no penhasco, atrativo que destaca o empreendimento dos demais, pois segundo a gerência é a segunda maior tirolesa do país, atraindo inúmeros turistas que gostam de aventuras radicais.

As diversas plantações existentes favorecidas pelas condições agronômicas atendem a demanda do consumo próprio do hotel, o que reduz os custos com 
matéria prima, e em época de safras as frutas são distribuídas aos hóspedes e funcionários, ampliando a satisfação dos mesmos. Chama também atenção o fato que o hotel dispõe de uma estrutura de acessibilidade para pessoas com mobilidade reduzida. Esta infraestrutura merece destaque por dificilmente ser encontrada nos hotéis deste segmento.

No que diz respeito aos recursos financeiros, o investimento do hotel A é proveniente do capital próprio dos sócios, além dos lucros de outro empreendimento que eles possuem. Inicialmente, não havia intenção de implementar um hotel-fazenda, o negócio surgiu após a compra da fazenda para outro empreendimento, mas,com o passar do tempo, os sócios decidiram investir na construção do hotel.

Sobre a mão de obra envolvida no empreendimento, relatou-se que a maioria dos colaboradores tem ensino médio, característica comum a outros hotéis do setor, e que apenas alguns gerentes possuem ensino superior. Chama atenção os funcionários serem considerados polivalentes pela gerência, pois além do domínio de suas funções aprendem diversas outra atividade no intuito de atender prontamente alguma demanda urgente. 0 próprio dono, como afirma a gestão, realiza funções diversas e operacionais quando necessário.

Para este empreendimento, o bom atendimento é algo essencial para que o hóspede se sinta a vontade, "como se estivesse entre amigos". A ideia é que os clientes criem vínculo com o hotel e com os funcionários e se sintam a vontade para dar algum tipo de feedback.

Quanto aos recursos organizacionais, a estrutura hierárquica do Hotel A é enxuta e aparentemente eficiente já que cada área possui um gerente específico. Existe, por exemplo, uma pessoa responsável por toda a logística de distribuição das atividades dos funcionários para melhor controle já que o hotel oferece diversas opções de lazer para os hóspede e turistas que compram o pacote day use, um pacote que inclui passar o dia no hotel aproveitando várias atividades e a estrutura do empreendimento.

Na visão da gerência, o hotel A tem uma boa posição em relação aos hotéis-fazenda da região em função da superestrutura que possui. Quanto aos diferenciais, as atividades de lazer e o atendimento foram os fatores citados, o que evidencia a importância dos recursos físicos e humanos para o sucesso do empreendimento. A seguir, apresenta-se o quadro que trata dos recursos encontrados no Hotel B e posteriormente uma análise mais detalhada dos mesmos.

\section{B) Hotel $B$}

Quadro 3 - Recursos do Hotel B

\begin{tabular}{l|l}
\multicolumn{1}{|c|}{ Características Hotel B } & \multicolumn{1}{c|}{ Recursos } \\
\hline $\begin{array}{l}\text { Infraestrutura condizente com o ambiente rural e da fazenda; } \\
\text { Localização e condições agronômicas vantajosas; } \\
\text { Diversidade de atividades de lazer; } \\
\text { Quartos amplos. }\end{array}$ & Físicos \\
\hline $\begin{array}{l}\text { 75\% dos investimentos foram feito através de empréstimos bancários. } \\
\text { 25\%Reserva de capital (capital próprio) }\end{array}$ & Financeiros \\
\hline
\end{tabular}

(continua...) 
Quadro 3 - Continuação

\begin{tabular}{l|l} 
Mão-de-obra qualificada; & Humanos \\
Funcionários polivalentes; & \\
Visão do gerente; & \\
Hospitalidade e atendimento diferenciado. & Organizacionais \\
\hline $\begin{array}{l}\text { Estrutura hierárquica; } \\
\text { Comprometimento dos funcionários; }\end{array}$ & \\
Política de responsabilidade sócio ambiental; & \\
Participação ativa em associações locais; & \\
Sistema de alimentação com as 3 refeições inclusas na diária;
\end{tabular}

Fonte: Dados da pesquisa

Quanto aos recursos físicos, o hotel B se destaca pela infraestrutura, adequada a proposta do ambiente rústico e da paisagem rural, o que chama atenção dos hóspedes. Outro recurso importante são os quartos dos hóspedes que além de serem bastante amplos $\left(40 \mathrm{~m}^{2}\right)$, dispõem de varanda com redário, itens que proporcionam maior conforto aos turistas e consequentemente maior satisfação em sua estadia.

O hotel está localizado em área de proteção ambiental, próximo das cachoeiras mais famosas da região, de um ponto turístico bastante visitado para apreciação do pôr do sol. É beneficiado pela geografia da região que proporciona um clima ameno e condições agronômicas vantajosas. Há plantações diversas de frutas, verduras, raízes e tubérculos que são utilizadas no consumo do hotel, algumas oferecidas aos turistas e outras vendidas.

A diversidade de atividades de lazer e a estrutura física disponível contribuem para a atratividade do hotel. Há, por exemplo, piscina com água clorada e também piscina com água natural para quem desejar ter essa experiência. Durante as atividades recreativas, existe a possibilidade de interação direta com a rotina do ambiente rural, como tirar leite de vaca, alimentar os animais e pesca. Essas ações condizem com a proposta real do turismo rural e contribuem para que os visitantes tenham uma experiência única na localidade.

Quanto aos recursos financeiros, a maior parte do capital investido no hotel advém de empréstimos bancários, cujos altos custos financeiros (juros) limitam o lucro do empreendimento. Apesar disso, a gerência mostra-se satisfeita com os resultados do negócio e afirma que conseguem lidar com as despesas envolvidas na manutenção e ampliação do hotel.

Conforme apontado por King (1995), a prática da hospitalidade pode ser um diferencial entre os concorrentes e fonte de vantagem competitiva, pois o objetivo é melhorar a satisfação do cliente. Neste ponto cabe ressaltar que os funcionários recebem atualizações constantes no que se refere a qualificação e que os proprietários participam ativamente do dia a dia do hotel, pois segundo a diretoria, existe uma política de bom atendimento na qual os clientes são literalmente atendidos pelos donos, isto para que seja possível alcançar a satisfação dos clientes.

A visão do gerente é destaque também no que diz respeito aos recursos humanos. Recentemente os proprietários iniciaram um investimento em máquinas de tijolos ecológicos para utilizar na expansão do hotel. A proposta é funcionar 
como um condomínio/hotel em decorrência da construção e venda de flats localizados no próprio empreendimento.

No que diz respeito aos recursos organizacionais, o organograma do Hotel B é bem definido e enxuto. Destaca-se neste empreendimento a preocupação com a responsabilidade sócio ambiental, sendo esta uma política perceptível na organização. Há, por exemplo, atividades desenvolvidas com a comunidade em datas festivas, a absorção da mão de obra local (80\% dos funcionários são da zona rural do município) e práticas como entrega do óleo de cozinha já utilizado para empresa especializada na reutilização e também utilização da sobra de alimentos para adubo.

A participação ativa em associações a nível municipal, estadual e federal e ainda a criação de uma associação local ressalta a atenção da gerência em desenvolver ações coletivas e integrar o trade turístico deste setor. Zonatto et al (2014) ressalta a importância das redes de cooperação no intuito de diferenciar as organizações das demais e buscar vantagem competitiva em relação as suas concorrentes.

No hotel existe a prática de comercializar o day use, comum entre os hotéis do setor,onde há também o sistema de alimentação com as 3 refeições inclusas na diária. Esta última informação pode ser vista como um diferencial, pois agrega valor ao empreendimento. Na opinião do diretor comercial, a localização, a paisagem, o clima, as opções de passeios e o atendimento são os fatores que mais diferenciam o hotel dos concorrentes da região.

\section{Gerando vantagem competitiva}

Levando em conta o modelo de VRIO de Barney e Hesterly (2011) foi possível avaliar quais recursos levavam a construção de vantagem competitiva sustentável em decorrência de seu valor, raridade, imitabilidade e da devida exploração pela organização. Os recursos foram evidenciados nos quadros a seguir:

Quadro 4 - Avaliação dos recursos do hotel A

\begin{tabular}{|c|c|}
\hline Características Hotel A & Recurso \\
\hline $\begin{array}{l}\text { Valioso: adaptado para receber deficientes, com vários elogios dos } \\
\text { clientes por meio de sites de viagens } \\
\text { Raro: após uma busca em sites de viagens nenhum hotel dessa categoria } \\
\text { mostrou ter capacidade superior de infraestrutura do hotel em análise, } \\
\text { considerando a região dada a certeza de concorrência direta } \\
\text { - Imperfeitamente imitável: nenhum hotel da região demonstra } \\
\text { capacidade para manter a mesma infraestrutura ou algo parecido } \\
\text { Explorados pela organização: condição geográfica do terreno contribui } \\
\text { além da imensa extensão }\end{array}$ & $\begin{array}{l}\text { Qualidade na } \\
\text { infraestrutura }\end{array}$ \\
\hline $\begin{array}{l}\text { - } \quad \text { Valioso: os clientes elogiam e divulgam aos amigos } \\
\text { - } \quad \text { Raro: poucos hotéis apresentam essa qualidade } \\
\text { - } \quad \text { Imperfeitamente imitável: cultura organizacional influencia } \\
\text { - } \quad \text { Explorados pela organização: qualificação SEBRAE como apoio }\end{array}$ & $\begin{array}{l}\text { Qualidade no } \\
\text { atendimento }\end{array}$ \\
\hline
\end{tabular}

(continua...) 
Quadro 4 - Continuação

\begin{tabular}{|c|c|}
\hline $\begin{array}{l}\text { - Valioso: fornecimento de matéria-prima e estímulo à gastronomia/ } \\
\text { turismo } \\
\text { - } \quad \text { Raro: nenhum hotel da região tema paisagem do hotel em análise } \\
\text { - Imperfeitamente imitável: aspecto geográfico } \\
\text { Explorados pela organização: condição geográfica do terreno contribui } \\
\text { além da imensa extensão }\end{array}$ & $\begin{array}{l}\text { Localização } \\
\text { Geográfica }\end{array}$ \\
\hline $\begin{array}{l}\text { - Valioso: união da força de trabalho, motivação e amor pelo que fazem } \\
\text { - } \quad \text { Raro: poucos hotéis conseguem motivar o funcionário, geralmente a } \\
\text { rotatividade é elevada } \\
\text { - Imperfeitamente imitável: cultura organizacional influencia } \\
\text { - Explorados pela organização: cultura organizacional influencia }\end{array}$ & $\begin{array}{l}\text { Comprome- } \\
\text { timento dos } \\
\text { funcionários }\end{array}$ \\
\hline
\end{tabular}

Fonte:Elaborado pelas autoras

Dos treze recursos encontrados (Quadro 2) apenas quatro proporcionaram à empresa uma vantagem competitiva sustentável, sendo eles a localização, a infraestrutura, a qualidade do atendimento e o comprometimento dos funcionários. A localização é um dos recursos físicos estratégicos importantes considerados por Barney e Hesterly (2011) e que se aplica com facilidade aos hotéis-fazenda.

No contexto da hotelaria, possuir um quarto com banheiro é algo bem comum entre os meios de hospedagem, logo, neste aspecto, não é um recurso raro, em contrapartida ter um quarto com vista para uma bela paisagem, como é o caso desse hotel em análise pode ser um recurso raro, já que alguns fatores tornam a imitação dos concorrentes mais difícil, como os fatores naturais (VASCONCELOS E CYRINO, 2000). Esta paisagem é explorada através da construção de um mirante "muito apreciada pelos turistas", segundo informações da gerência.

Contar com uma estrutura que permite acesso a deficientes pode ser considerado valioso e raro já que nem todos os hotéis desta categoria possuem, entretanto não é difícil imitar e explorá-los, por isso gerará apenas vantagem competitiva temporária para a empresa (BARNEY E HESTERLY, 2011). Por outro lado a infraestrutura do hotel como todo pode ser considerado como vantagem competitiva sustentável já que é difícil de ser imitada pelos altos custos envolvidos.

Embora as condições agronômicas sejam vantajosas, pois é um recurso valioso em que com a produção de alimentos acarreta uma diminuição nos gastos do hotel, não se trata de um recurso raro, pois geralmente este tipo de empreendimento é construído em fazendas onde a terra possui qualidade para o plantio e esta é uma prática comum dos hotéis deste segmento. Esse recurso possibilita, portanto uma paridade competitiva, isto significa que se não devidamente explorado gerará uma desvantagem principalmente de custos (BARNEY E HESTERLY, 2011).

Da mesma forma acontece com a diversidade de atividades de lazer e os espaços diferenciados para o público infantil, pois estes são recursos presentes em diversos empreendimentos do setor. Portanto, mesmo sendo valiosos para exploração das oportunidades como o desenvolvimento do marketing boca a boca através das crianças, esses recursos não são raros, e geram apenas paridade competitiva.

Acompanhe a seguir a avaliação dos recursos do hotel B e em seguida um detalhamento melhor das relações estabelecidas. 
Quadrro 5 - Avaliação dos recursos hotel B

\begin{tabular}{|c|c|}
\hline Características Hotel B & Recurso \\
\hline $\begin{array}{l}\text { - Valioso: proximidade com os clientes e visão a longo prazo } \\
\text { - } \quad \text { Raro: capacidade empreendedora } \\
\text { - Imperfeitamente imitável: conhecimento e motivação dificulta a imitação } \\
\text { dos concorrentes } \\
\text { - Explorados pela organização: ampliação do hotel com ideias de } \\
\text { preservação ambiental }\end{array}$ & $\begin{array}{l}\text { Visão do } \\
\text { gerente }\end{array}$ \\
\hline $\begin{array}{l}\text { - Valioso: há uma proximidade entre cliente e a organização } \\
\text { - } \quad \text { Raro: poucos hotéis apresentam essa qualidade } \\
\text { - Imperfeitamente imitável: cultura organizacional influencia } \\
\text { - } \quad \text { Explorados pela organização: qualificação SEBRAE como apoio }\end{array}$ & $\begin{array}{l}\text { Qualidade no } \\
\text { atendimento }\end{array}$ \\
\hline $\begin{array}{l}\text { - Valioso: fornecimento de matéria-prima e estímulo ao turismo da região } \\
\text { - } \\
\text { - } \quad \text { Imponto turístico importante dentro da propriedade } \\
\text { - Explorados pela organização: proximidade de pontos turísticos para } \\
\text { atrair clientes }\end{array}$ & $\begin{array}{l}\text { Localização } \\
\text { Geográfica }\end{array}$ \\
\hline $\begin{array}{l}\text { - Valioso: União da força de trabalho e principalmente zelo com os } \\
\text { hóspedes/clientes } \\
\text { Raro: poucos hotéis conseguem motivar o funcionário, geralmente a } \\
\text { rotatividade é elevada } \\
\text { - Imperfeitamente imitável: cultura organizacional influencia } \\
\text { - Explorados pela organização: cultura organizacional influencia }\end{array}$ & $\begin{array}{l}\text { Comprome- } \\
\text { timento dos } \\
\text { funcionários }\end{array}$ \\
\hline
\end{tabular}

Fonte: Elaborada pelas autoras

O quadro revela que, dos dezesseis recursos identificados no Hotel B, apenas quatro geram vantagem competitiva sustentável. Isso se dá pelo fato destes recursos serem valiosos, raros, difíceis de imitar e explorados pela organização. No Hotel A o número de recursos que geram este tipo de vantagem foi o mesmo do Hotel $\mathrm{B}$, embora a quantidade total de recursos identificados tenha sido menor (16 no hotel B e 13 no hotel A).

A localização é um importante recurso estratégico para ambos os hotéis pesquisados. Localizado em área de preservação ambiental, com clima agradável e próximo a importantes pontos turísticos da região, alguns inclusive dentro de seu espaço, o Hotel B tem nesse recurso raro e difícil de imitar, uma de suas principais forças no mercado.

Semelhante ao Hotel A, as condições agronômicas e a diversidade de atividades de lazer geram paridade competitiva para o Hotel B, pois não são raros nem difíceis de imitar. 0 mesmo acontece com os recursos financeiros, a mão de obra qualificada, os funcionários polivalentes e o sistema de alimentação com as três refeições incluídas. Apesar do Hotel A não possuir este último recurso em sua organização, viu-se que é uma prática comum a outros hotéis rurais do Estado de Pernambuco após análise de site de viagens.

0 atendimento diferenciado é quase uma "marca registrada" em empreendimentos deste setor. Em ambos os hotéis, percebeu-se que há uma grande ênfase no que diz respeito à qualidade do atendimento e a hospitalidade, este último em conformidade com Andrade e Polo (2016) que propuseram um modelo teórico 
em que segundo gestores e clientes consideram a hospitalidade um recurso estratégico para a hotelaria e assim potencial geradora de vantagem competitiva.

No hotel B, há a participação ativa dos proprietários no atendimento direto ao hóspede. Destaca-se o fato dos donos receberem os turistas prestando o máximo de atenção em suas demandas ao longo da estadia, sempre no intuito de que estes saiam satisfeitos e retornem em breve.

A visão do gerente é outro recurso humano que merece destaque no hotel B. É notável no discurso da gerência a intenção de ampliar o negócio e melhorar a infraestrutura do local, arcando por vezes com custos que seriam de responsabilidade do poder público, por exemplo. Há também a visão de coletivismo, como a participação em associações, e de sustentabilidade, que incluem as ações de responsabilidade socioambiental adotadas pelo hotel. Estes aspectos evidenciam que a visão do gerente, assim como o comprometimento dos funcionários, gera vantagem competitiva sustentável para o empreendimento.

\section{CONSIDERAÇões finats}

A partir das informações obtidas nesta pesquisa, percebe-se que os hotéis-fazenda estão inseridos no dinâmico setor do turismo rural com um posicionamento que pode ser considerado estratégico para o desenvolvimento desta atividade. A integração com a comunidade local e a valorização das práticas rurais são fatores que podem fortalecer a cultura do campo e auxiliar na preservação da natureza destas localidades.

Diferentemente dos hotéis localizados em áreas urbanas, os hotéis-fazenda geralmente não trabalham com economia de escala, pois possuem um número reduzido de quartos e para alcançar uma boa lucratividade precisam explorar outros recursos, como por exemplo, a localização em um ambiente atrativo e agradável, que possibilite o contato mais próximo com a natureza e com o modo de viver do campo. Percebe-se, portanto, que este recurso físico é de fundamental importância para este tipo de empreendimento, podendo gerar uma vantagem competitiva sustentável como visto em ambos os casos em estudo.

No que tange aos recursos organizacionais destaca-se o comprometimento dos colaboradores e envolvimento destes no ambiente de trabalho buscando gerar mais satisfação entre os clientes. Quanto aos recursos humanos, o atendimento e hospitalidade são também pontos de destaque em ambos os casos em análise, além da diversidade de atrativos e atividades de lazer que são desenvolvidas em cada localidade. Destaca-se, por exemplo, a prática adotada pelos proprietários de receber diretamente os turistas e sempre que necessário conversar com os mesmos para resolver eventuais reclamações, dando ênfase a estes feedbacks para aprimoramento do serviço.

Pode-se inferir, portanto, que os recursos físicos e humanos, especialmente a localização e o atendimento, possuem clara relevância diante dos demais recursos de um hotel-fazenda no que diz respeito à geração de vantagem competitiva sustentável para os mesmos. Diversos outros recursos, como as políticas de sustentabilidade, a participação em associações locais e a adaptação da infraestrutura para maior acessibilidade, podem e devem ser explorados nesse intuito. Embora, é preciso perceber que enquanto estes recursos foram passíveis de imi- 
tação irão gerar apenas uma vantagem competitiva temporária ou uma paridade competitiva, no caso de não serem raros.

É válido lembrar que os estudos de caso analisados não tinham pretensão de comparação, mas de descrever detalhadamente os recursos que cada um possuía em sua particularidade e realidade local. Entretanto, algumas comparações foram realizadas durante as análises no intuito de facilitar o entendimento e melhor discutir a teoria trabalhada.

Uma das contribuições trazidas por esta análise é o de utilizar um modelo simples e prático como o VRIO para avaliar os recursos estratégicos de forma objetiva em pesquisas de cunho científico. A partir da abordagem qualitativa, neste caso baseada nos discursos dos gestores dos hotéis-fazenda pesquisados, tornou-se possível identificar e avaliar os recursos estratégicos que sustentam a vantagem competitiva dos empreendimentos pesquisados.

Embora os hotéis-fazenda apresentem posição de destaque no setor do turismo rural, a visão da RBV apresentou uma perspectiva nova e talvez "nunca" imaginada de análise para esses gestores, principalmente no que se refere à devida importância da exploração dos seus recursos de forma estratégica. Dessa forma, além das contribuições acadêmicas que este estudo proporciona, há também contribuição mercadológica para os estrategistas envolvidos neste segmento.

Como em toda pesquisa científica, algumas limitações foram encontradas e precisam ser citadas. A maior delas consistiu na dificuldade para encaixar alguns recursos específicos dos hotéis-fazenda na definição de Barney e Hesterly (2011), pois embora a classificação estivesse clara, o setor de hotelaria apresenta características peculiares que não abordadas por estes autores. Por outro lado, não foram encontradas outras classificações que pudessem atender às expectativas deste estudo.

Com base nas limitações identificadas, surgem oportunidades para novas pesquisas, como, por exemplo, a construção de um modelo de avaliação de recursos que pudesse atender às características do setor de hotelaria e, mais especificamente, de empreendimentos localizados em ambiente natural como os hotéis-fazenda. Assim poder-se-ia alinhar os estudos na RBV com a hotelaria e o turismo rural.

\section{REFERÊNCIAS}

ANDRADE, D. A. da C.; POLO, E. F..Hospitalidade como Recurso Estratégico na Hotelaria: Proposição de um Modelo Conceitual.In: Anais do Encontro Anual da Associação Nacional de Pós-Graduação em Administração, XL EnANPAD, Costa do Sauípe-BA, 2016.

BARRETTO, M. Planejamento e organização em turismo. 9. ed. Campinas: Papirus, 1991.

BARNEY, J.B. Firm Resources and Sustained Competitive Advantage. Journal of Management, v. 17, n. 1, p. 99-120, 1991.

BARNEY, J.B.; HESTERLY, W. S. Administração estratégica e vantagem competitiva. $3^{a}$ Ed. São Paulo: Pearson Prentice Hall, 2011.

BENI. M. C. Conceituando turismo rural, agroturismo, turismo ecológico e ecoturismo. In: BARRETTO, Margarita e TAMANINI, Elizabeth. (Org.). Redescobrindo a ecologia no turismo. Caxias do Sul: EDUCS, p. 31-34, 2002. 
BOSWORTH, G.; FANNELL, H. Tourism entrepreneurship in North umberland. Annals of Tourism Research, 38(4), 1474-1494, 2011.

BRASIL. Ministério do Turismo. Turismo rural: orientações básicas. Secretaria Nacional de Políticas de Turismo. Brasília, 2008.

BRASIL. Ministério do Turismo. Cartilha Turismo Rural. Brasília, 2013. . Diretrizes para o Desenvolvimento do Turismo Rural. Brasília, 2003.

. Hábitos de Consumo do Turismo Brasileiro. Brasília, 2009. Disponível em <http:// www.turismo.gov.br/sites/default/turismo/noticias/todas_noticias/Noticias_download/13.11.09_Pesquisa_Hxbitos_2009.pdf >. Acesso em: 15 out. 2015.

BROOKER, E.; JOPPE, M. Rural Tourism: An Internal Perspective on Challenges and Innovation. Journal of Tourism, vol. XIV, n. 1, 2013.

CANDIOTTO, L. Z. P.Elementos para o Debate Acerca do Conceito de Turismo Rural. Turismo em Análise, Vol. 21, n. 1, abril 2010.

GIL, A. C. Como elaborar projetos de pesquisa. 4 ed. São Paulo: Atlas, 2009.

GOHR, C. F.; SANTOS, L. C.. Estratégias Competitivas para Empresas Turísticas: um estudo no setor hoteleiro de um município do litoral catarinense. Turismo em análise, Vol. 21, n. 2, agosto 2010 .

GOHR, C. F.; MORETTO NETO, L.; SANTANA, E. A. Estratégias competitivas: um estudo no setor hoteleiro de Itapema/SC. Turismo - Visão e Ação. V. 4, n. 10, 2002.

GORINI, A. P. F.; MENDES, E. da F. Setor de turismo no Brasil: segmento de hotelaria. BNDES Setorial, Rio de Janeiro, n. 22, p. 111-150, set. 2005.

GRANT, R. M. The resource-based theory of competitive advantage: implications for strategy formulation. California Management Review, v.33, n.3, p.114-135, Spring, 1991.

KIN, C.. A. What is hospitality?International Journal of Hospitality Management,14, 314, p. 219-234, 1995.

LOHMANN, G.; PANOSSO NETTO, A. Teoria do turismo: conceitos, modelos e sistemas. São Paulo: Aleph, 2008.

OKECH R.; HAGHIRI, M.; GEORGE, B. P. Rural tourism as a sustainable development alternative: analysis with special reference to Luanda, Kenya. CULTUR - Revista de Cultura e Turismo, ano 06, n. 03, ago. 2012.

PETERAF, M. A. The cornerstones of competitive advantage: a resource-based view. Strategic Management Journal, v. 14, p. 179-191, 1993.

PENROSE, E. A teoria do crescimento das firmas. São Paulo: Editora Unicamp, 2006.

PORTER, Michael. Estratégias competitivas: técnicas para análise de indústrias e da concorrência. Rio de Janeiro. Campus, 1986

QUADROS, A. H. de. A hospitalidade e o diferencial competitivo das empresas prestadoras de serviço. Revista Hospitalidade. São Paulo, v. VIII, n. 1, p. 43-57, jan.jun. 2011.

ROQUE, A. M.; VIVAN, A. M.. Turismo no espaço rural: uma estratégia para a nova gestão rural brasileira. Revista de Administração da UFLA, v.1, n. 1,jan.-jun. 1999.

SANTOS, S. B. S. Estratégias empresariais adotadas pela hotelaria em clusters turísticos no estado de São Paulo. São Paulo, Universidade Paulista, UNIP, 2007.

SANTOS, L. C.; GOHR, C. F.; CRUZ, I. K. H. Avaliação de recursos estratégicos em empresas hoteleiras de um município sul-mato-grossense. Revista Brasileira de Estratégia, Curitiba, v. 4, n. 3, p. 231-243, set./dez. 2011. 
SILVA, F. F.; BARRETO, L. M. T. da S. Estratégias competitivas em turismo: o caso do Cirque du Soleil. Revista Hospitalidade. São Paulo, v. XII, n. 1, p. 370-386, jun. 2015.

SILVA, M. F.; ALMEIDA, J. A.Turismo rural: família, patrimônio e trabalho. In: RIEDL, M.; ALMEIDA, J. A.; VIANA, A. L. B. (Org.). Turismo rural: tendências e sustentabilidade. Santa Cruz do Sul: EDUNISC, p. 165-203, 2002.

SOUZA,V. da S.; SOBRAL, M. F. F.; MELO, A. S. Práticas socioambientais em hotéis-fazenda do Agreste Pernambucano sob a perspectiva do cliente. Revista Metropolitana de Sustentabilidade - RMS, São Paulo, v. 5, n. 3, p. 104-130, set./dez. 2015.

STOKES, R. Tourism strategy making: insights to the events tourism domain. Tourism Management, v. 29, n. 2, p. 252-262, 2008.

TSAI, H.; KEVIN, H. S.; WONG, F. Tourism and hotel competitiveness research. Journal of Travel \& Tourism Marketing, 26:5-6, 522-546, 2009.

TULIK, O. Turismo Rural. São Paulo: Aleph, 2003.

VASCONCELOS, F. C.; BRITO, L. A. L. Vantagem competitiva:o construto e a métrica. Revista de administração, v.44,n.2, p.70-82, 2004.

VASCONCELOS, F.C; CYRINO, A, B. Vantagem competitiva: os modelos teóricos atuais e a convergência entre estratégia e teoria organizacional. In: Revista de Administração de empresas, v.40, n.4,out/dez.,p.20-37. 2000.

WERNERFELT, B. A resource-based view of the firm. Strategic Management Journal, Chicago, v.5,p.171-180, 1984.

WILKE, E. P.; RODRIGUES, L. C.. Fontes de pressão institucional: reflexões sobre legitimidade na indústria hoteleira brasileira.Revista Brasileira de Pesquisa em Turismo. São Paulo, 7(2), p. 337-357, maio/ago. 2013.

YIN, R.K. Estudo de Caso: Planejamento e Métodos. 3a ed. Editora: Bookman. Porto Alegre, 2005.

ZONATTO, V. C. da S.; SCHUH, C.; ZONATTO, P. A. F.. Contribuição dos Recursos Estratégicos nos Processos de Criação da Inovação em uma Rede de Cooperação Hoteleira. Turismo em Análise, vol. 25, n. 3, dez, 2014.

Recebido em: $15 / 02 / 2017$

Aprovado em: 05/10/2017

\section{Contribuição}

Luana de Oliveira Alves: definição do Problema de Pesquisa e objetivos;

DESENVOLVIMENTO DA PROPOSIÇÃo TEÓRICA; REALIZAÇÃo DA REVISÃo BIBLIOGRÁFICA E FUNDAMENTAÇÃo TEÓRICA; ESCOLHA DOS PROCEDIMENTOS METODOLÓGICOS; COLETA DE DADOS; ANÁLISE DE DADOS; ELABORAÇÃO DE TABELAS, GRÁFICOS E FIGURAS; REDAÇÃO DO MANUSCRITO; ADEQUAÇÃO DO MANUSCRITO ÀS NORMAS DA RTA.

Luana Alexandre Silva: definição do problema de pesquisa e objetivos; desenvolvimento da proposição teórica; realização da revisão bibliográfica e fundamentação teórica; escolha dos procedimentos metodológicos; coleta de dados; análise de dados; elaboração de tabelas, gráficos e figuras; redação do manuscrito.

Viviane Santos Salazar: análise de dados; elaboração de tabelas, gráficos e figuras; revisão crítica do manuscrito; redação do manuscrito. 